\title{
R.O. Dzumedzey \\ Scattering of Charge Carriers in Thin Films PbTe:Bi
}

\author{
Vasyl Stefanyk Precarpathian National University, Ivano-Frankivsk, 76018, Ukraine, E-mail: kepa@nashemisto.if.ua
}

The calculations of the scattering mechanisms of charge carriers in thin films of PbTe:Bi with 1 at. \% of bismuth is carried out. The dominant mechanisms of scattering in the investigated samples are determined. The thickness dependence of the ratio $\mu_{\text {surf }} / \mu_{\text {bulk }}$ is considered.

Keywords: Lead telluride, doping, scattering of charge carriers, mobility.

Work arrived to the editor 01.06.2019; accepted for printing15.06.2019.

\section{Introduction}

The last two decades have demonstrated rapid growth in the interest of scientists in the practical realization of research results in thermoelectricity. First of all, this is the desire of humanity to receive safe and clean energy [1-3]. Thermoelectric transformation of energy is precisely this and stands out. There is no combustion of fossil fuels, no mechanical work to convert one kind of energy (for example, thermal or mechanical) into electric. Thermoelectric effects are due only to the existence of a pair of materials of n- and ptype conductivity or a set of such pairs for a more powerful end result in energy generation.

Thermoelectric energy conversion is relevant for several reasons: reliability and durability in work (due to the lack of moving mechanisms), environmental friendliness (no combustion of fuel for generating electricity and use of waste heat, which reduces the global contribution to the greenhouse effect). The use of thin-film structures leads to an improvement in the output of thermoelectric characteristics, and reduces the amount of material used [4-5]. At present, the vapor phase technologies of formation of the structure of thin film micromodule for the temperature range (450-800) K are actively investigated on the basis of multicomponent thermoelectric materials of the type $\mathrm{PbTe}: \mathrm{Bi}(\mathrm{Sb})$,
$\mathrm{PbTeBi}_{2}\left(\mathrm{Sb}_{2}\right) \mathrm{Te}_{3}, \mathrm{PbTe}-\mathrm{SnTe}, \mathrm{Pb}-\mathrm{Ag}-\mathrm{Sb}-\mathrm{Te}(\mathrm{LAST})$ or $\mathrm{Pb}-\mathrm{Sn}$-Ag-Te (LATT).

Thin films are of interest to researchers because of their different peculiarities. On the one hand, it is an opportunity to significantly improve certain properties, in particular, and thermoelectric, by reducing the dimension [6-9]. On the other hand, an important role is played by the miniaturization of end devices. On the basis of thin films, it is possible to create thermoelectric micromodules that will be practical for miniature devices, where conventional thermoelectric modules cannot be fitted due to their dimensions $[3,10]$.

\section{Experiment}

The thin films were obtained by evaporation in an open vacuum of a pre-synthesized compound $\mathrm{PbTe}: \mathrm{Bi}$ with 1 at.\% bismuth. As substrates, we used sital plates, which were subjected to preliminary chemical purification. Evaporation temperature was $T_{E}=970 \mathrm{~K}$, deposition temperature $-\mathrm{T}_{\mathrm{D}}=470 \mathrm{~K}$, and the deposition time was from $3 \mathrm{~s}$ to $\tau=120 \mathrm{~s}$. Technological parameters for obtaining samples are given in Table 1 .

The synthesis of the starting material was performed by fusing the components in the vacuumed ampoules of quartz glass (Pirex). The ampoules were made of tubes

Table 1

Technological factors for the condensate precipitation of $\mathrm{PbTe}: \mathrm{Bi}$ in an open vacuum on a sital substrates

\begin{tabular}{|c|c|c|c|}
\hline N sample & Evaporation temperature $\mathrm{T}_{\mathrm{E}}, \mathrm{K}$ & Deposition temperature $\mathrm{T}_{\mathrm{D}}, \mathrm{K}$ & Deposition time $\tau, \mathrm{s}$ \\
\hline 1 & 970 & 470 & 3 \\
\hline 2 & 970 & 470 & 15 \\
\hline 3 & 970 & 470 & 60 \\
\hline 4 & 970 & 470 & 120 \\
\hline
\end{tabular}


Results of Hall measurements of investigated samples (at $300 \mathrm{~K}$ )

\begin{tabular}{|c|c|c|c|c|}
\hline N sample & $\mathrm{R}_{\mathrm{H}}, \mathrm{cm}^{3} / \mathrm{C}$ & $\mathrm{n}, \mathrm{cm}^{-3}$ & $\mu, \mathrm{cm}^{2} / \mathrm{Vs}$ & $\mathrm{D}, \mathrm{nm}$ \\
\hline 1 & 0.60 & $1.0 \cdot 10^{19}$ & 12 & 54 \\
\hline 2 & 0.23 & $2.7 \cdot 10^{19}$ & 50 & 169 \\
\hline 3 & 0.13 & $4.7 \cdot 10^{19}$ & 51 & 891 \\
\hline 4 & 0.25 & $2.5 \cdot 10^{19}$ & 75 & 1890 \\
\hline
\end{tabular}

Data from the analysis of AFM-studies of investigated samples

\begin{tabular}{|c|c|c|c|c|c|c|}
\hline $\begin{array}{c}\mathrm{N} \\
\text { sample }\end{array}$ & $\begin{array}{c}\text { Average } \\
\text { height } \\
\mathrm{h}_{\mathrm{a}}, \mathrm{nm}\end{array}$ & $\begin{array}{c}\text { Maximum value } \\
\text { of lateral } \\
\text { dimensions } \\
\mathrm{d}_{\mathrm{m}}, \mathrm{nm}\end{array}$ & $\begin{array}{c}\text { Average value } \\
\text { of lateral } \\
\text { dimensions } \\
\mathrm{d}_{\mathrm{a}}, \mathrm{nm}\end{array}$ & $\begin{array}{c}\text { Ratio of the maximum } \\
\text { value of lateral } \\
\text { dimensions to the } \\
\text { average } \\
\mathrm{d}_{\mathrm{m}} / \mathrm{d}_{\mathrm{a}}, \mathrm{nm}\end{array}$ & $\begin{array}{c}\text { Average } \\
\text { roughness } \\
\mathrm{R}_{\mathrm{a}}, \mathrm{nm}\end{array}$ & $\begin{array}{c}\text { Average } \\
\text { square } \\
\text { roughness } \\
\mathrm{R}_{\mathrm{q}}, \mathrm{nm}\end{array}$ \\
\hline 1 & 6 & 49 & 29 & 1.7 & 0.5 & 0.6 \\
\hline 3 & 19 & 78 & 44 & 1.8 & 1.8 & 2.4 \\
\hline 4 & 53 & 133 & 80 & 1.6 & 3.2 & 4.4 \\
\hline
\end{tabular}

with an outer diameter of $20 \mathrm{~mm}$ and a wall thickness of $2 \mathrm{~mm}$. Before loading, the ampoules were cleaned with a mixture of nitric and hydrochloric acid. For synthesis, AlfaAesar products of purity of $99.999 \%$ were used. Pumping out was carried out to a pressure of $10^{-4} \mathrm{~Pa}$ using a vacuum post HiCubeEco.

On the thin films obtained, Hall measurements were made in constant electric and magnetic fields, as well as AFM images of PbTe: Bi nanostructures were obtained.

\section{Elements of the theory of calculating carrier mobility}

For the calculations of the mobility of carriers in the bulk material, we used a variation method in which, as a rule, a test function is selected in the form of a series of degrees of energy, the coefficients of which are variation parameters and determined by the condition of the best matching of theoretical and experimental results [11]. Equations for calculation are described in detail in [12].

The features of charge carriers scattering in a bulk PbTe:Bi material with different bismuth content $(0.25$,
$0.5,1$ and 2 at.\%) in the wide temperature range (300$800 \mathrm{~K})$ are presented in papers [13-14]. It is established that in bulk materials the dominant scattering mechanism is impurity scattering.

If we consider the films, then we need to consider additional mechanisms that determine the charge carriers scattering. In particular, this is the influence of the surface and grain boundaries.

Analytically, the contribution of the surface and grain boundaries to total mobility can be expressed as a ratio:

$$
\frac{\mu_{\text {surf }}}{\mu_{\text {bulk }}}=1-\frac{3 \lambda}{8 D}(1-p)
$$

and

$$
\frac{\mu_{\text {grain }}}{\mu_{\text {bulk }}}=\frac{1}{1+1.34\left(\frac{R}{R-1}\right) \frac{\lambda}{d_{\text {grain }}}},
$$

respectively, where $\lambda$ is the length of free run, $\mathrm{D}$ is film thickness, $\mathrm{p}$ is the reflection coefficient of the surface, $\mathrm{R}$ is the reflection coefficient of the grain boundaries, and $d_{\text {grain }}$ - the average grain size [15].
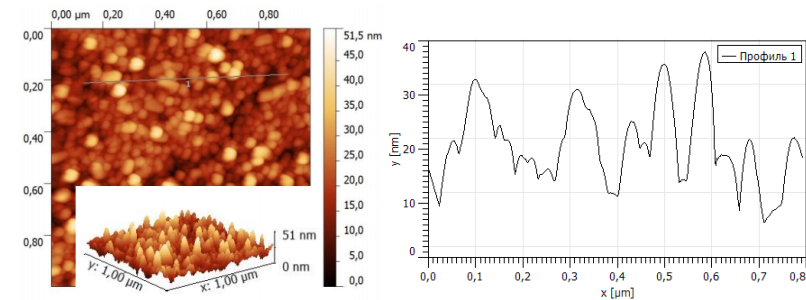

a)
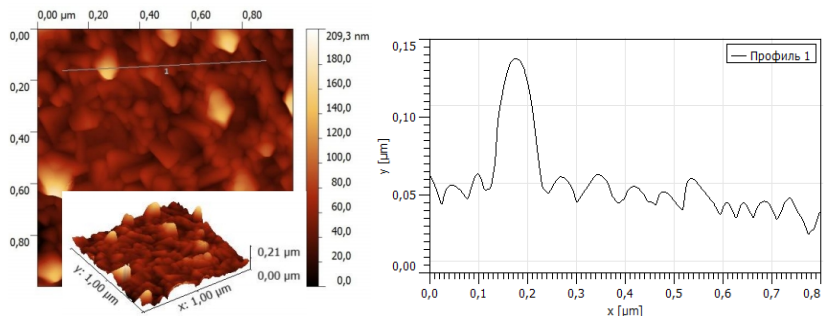

b)

Fig. 1. AFM images of samples PbTe:Bi with 1 at.\% bismuth: a - sample 2, b - sample 3. 


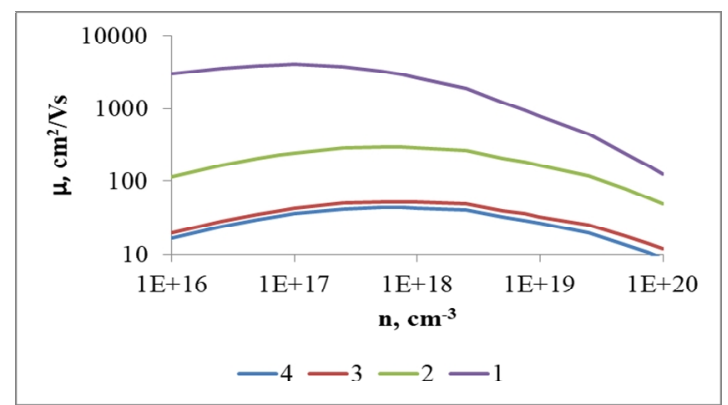

a)

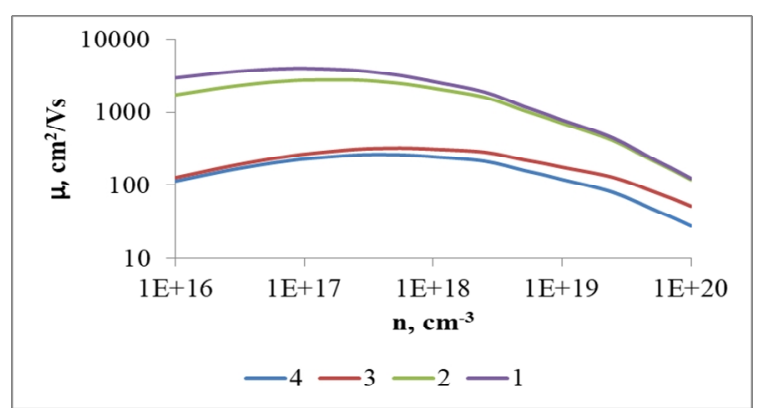

b)

Fig. 2. Concentration dependence of mobility (1- scattering of bulk material, 2- surface scattering, 3- scattering on grain boundaries, 4- total scattering) of thin films

PbTe:Bi with 1 at.\% bismuth: a - sample 1, b- sample 4.

Calculated data of total motility of thin films PbTe:Bi with 1 at.\% bismuth

Table 4.

\begin{tabular}{|c|c|c|c|c|}
\hline N sample & $300 \mathrm{~K}$ & $450 \mathrm{~K}$ & $600 \mathrm{~K}$ & $800 \mathrm{~K}$ \\
\hline 1 & 26 & 14 & 7 & 4 \\
\hline 2 & 59 & 33 & 17 & 9 \\
\hline 3 & 57 & 30 & 15 & 8 \\
\hline 4 & 80 & 45 & 23 & 12 \\
\hline
\end{tabular}

\section{Analysis of results}

The results of the Hall measurements of investigated samples (N. 1-4) are presented in Table 2. The AFM image of the samples and the data from the analysis of AFM-studies are presented in Fig. 1 and table 3 respectively.

Using the experimental data (tables 2 and 3) and the results of studies [13-14] using the equation (1) and (2), the contribution of individual scattering mechanisms to the total mobility was calculated.

As can be seen from the concentration dependences of mobility (Fig. 2), the dominant mechanism is scattering on the grain boundaries (Fig. 2, curves 3). The

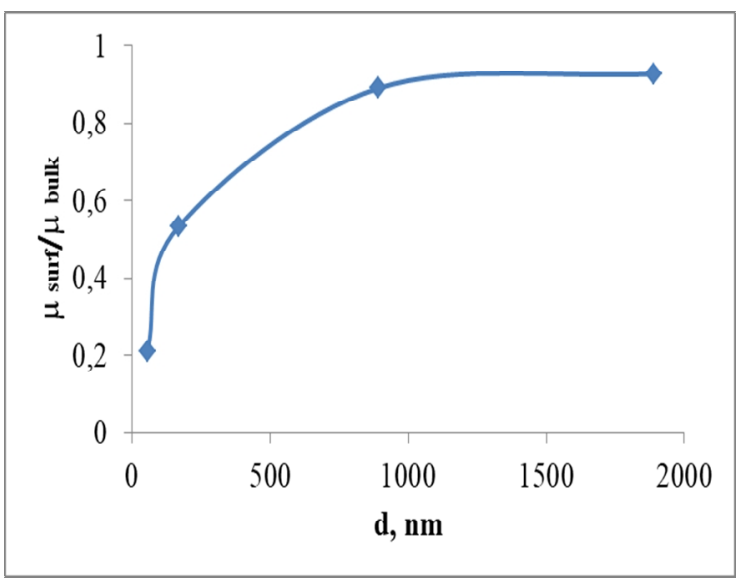

Fig. 3. Ratio of $\mu_{\text {surf }} / \mu_{\text {bulk }}$ to the thickness of the samples. contribution of the surface to total mobility (Fig. 2, curves 2) varies. If for the sample 1 (Fig. 2, a) the contribution of the surface is significant, for the sample 4 (Fig. 2, b), the contribution of the surface is proportional to the total scattering mechanisms of the bulk material. This behavior is due to a change in the thickness of the samples.

Ratio $\mu_{\text {surf }} / \mu_{\text {bulk }}$ from the samples thickness is presented in Fig. 3. The proximity of the ratio $\mu_{\text {surf }} / \mu_{\text {bulk }}$ to unity indicates that the total mobility of these scattering mechanisms, which is obtained taking into account the Mattisen rule, is determined mainly by the scattering mechanisms inherent in bulk materials. From Fig. 3 it is noticeable that the contribution of surface scattering disappears in the thin films with thicknesses from $1000 \mathrm{~nm}$ and above.

Table 4 shows the calculated data of total mobility of thin films PbTe:Bi with 1 at.\% bismuth for a wide temperature range (300-800 K). Good agreement of the calculation (Table 4) and experimental data (Table 2) indicates the correct choice of theoretical approaches.

\section{Conclusions}

1. The dominance of scattering on grain boundaries for all investigated samples of thin films PbTe:Bi with 1 at.\% bismuth is indicated.

2. It is established that the contribution of surface scattering disappears in the thin films with thicknesses from $1000 \mathrm{~nm}$ and above.

3. The expediency of using the proposed theoretical approaches for calculating the mobility of charge carriers in thin films is proved. 
The work was carried out within the framework of the project of the MES of Ukraine, the state registration number $0119 U 100062$.
R.O. Dzumedzey - researcher.

[1] J. Mao, Z. Liu, Z. Ren, Quant. Mater., 1, 16028 (2016) (https://doi.org/10.1038/npjquantmats.2016.28).

[2] Chao HAN, et al., Advanced Energy Materials, 6(15), 1600498 (https://doi.org/10.1002/aenm.201600498).

[3] G. Bulman, P. Barletta, J. Lewis, N. Baldasaro, M. Manno, A. Bar-Cohen, B. Yang, Nature communications, 7, 10302 (2016) (https://doi.org/10.1038/ncomms10302).

[4] Ihtesham Chowdhury, et al., Nature nanotechnology, 4.4: 235 (2009).

[5] Rama Venkatasubramanian, et al., Thin-film thermoelectric devices with high roomtemperature figures of merit. (Materials for Sustainable Energy, 2011).

[6] L.D. Hicks, \& M.S. Dresselhaus, Physical Review B, 47(19), 12727 (1993).

[7] Y. Lan, A.J. Minnich, G. Chen, Z. Ren, Advanced Functional Materials, 20(3), 357 (2010).

[8] H. Alam, S. Ramakrishna, Nano energy, 2(2), 190 (2013).

[9] D. Ding, D. Wang, M. Zhao, J. Lv, H. Jiang, C. Lu, Z. Tang, Advanced Materials, 29(1), 1603444 (2017) (https://doi.org/10.1002/adma.201603444).

[10] I.A. Moskalyk, Physics and Chemistry of Solid State, 16(4), 742 (2015) (doi:10.15330/pcss. 16.4.742-746).

[11] D.M. Zayachuk, FTP., 31(2), 217 (1997).

[12] D.M. Freik, L.I. Nukuruy, R.O. Dzumedzey, O. Zub, Physics and Chemistry of Solid State, 11(1), 62 (2010).

[13] R.O. Dzumedzey, Physics and Chemistry of Solid State, 12(1), 69 (2011).

[14] L.I. Nukuruy, R.O. Dzumedzey, M.O. Galushak, T.P. Gevak, Yu.V. Bandura, Physics and Chemistry of Solid State, 12(3), 589 (2011).

[15] L.I. Nykyruy, O.M. Voznyak, Y.S. Yavorskiy, V.A. Shenderovskiy, R.O. Dzumedzey, O.B. Kostyuk, R.I. Zapukhlyak, Journal of Thermoelectricity, 3, 15 (2018).

\title{
Р.О. Дзумедзей
}

\section{Розсіювання носіїв заряду в тонких плівках PbTe:Bi}

\author{
Прикарпатський наиіональний університет імені Василя Стефаника, \\ м. Івано-Франківськ, 76018, Україна, E-mail: kepa@nashemisto.if.ua
}

\footnotetext{
Проведено розрахунки механізмів розсіювання носіїв заряду в тонких плівках $\mathrm{PbTe:Bi} \mathrm{iз} 1$ ат.\% вісмуту. Визначено домінуючі механізми розсіювання в досліджуваних зразках. Розглянуто товщинні залежності співвідношення $\mu_{\text {surf }} / \mu_{\text {bulk }}$.

Ключові слова: плюмбум телурид, легування, розсіювання носіїв заряду, рухливість.
} 